\title{
Artificial Neural Networks for Event Based Rainfall-Runoff Modeling
}

\author{
Archana Sarkar, Rakesh Kumar \\ National Institute of Hydrology, Roorkee, India \\ Email: archana@nih.ernet.in
}

Received March 11, 2012; revised May 19, 2012; accepted August 12, 2012

\begin{abstract}
The Artificial Neural Network (ANN) approach has been successfully used in many hydrological studies especially the rainfall-runoff modeling using continuous data. The present study examines its applicability to model the event-based rainfall-runoff process. A case study has been done for Ajay river basin to develop event-based rainfall-runoff model for the basin to simulate the hourly runoff at Sarath gauging site. The results demonstrate that ANN models are able to provide a good representation of an event-based rainfall-runoff process. The two important parameters, when predicting a flood hydrograph, are the magnitude of the peak discharge and the time to peak discharge. The developed ANN models have been able to predict this information with great accuracy. This shows that ANNs can be very efficient in modeling an event-based rainfall-runoff process for determining the peak discharge and time to the peak discharge very accurately. This is important in water resources design and management applications, where peak discharge and time to peak discharge are important input variables.
\end{abstract}

Keywords: Artificial Neural Networks (ANNs); Event Based Rainfall-Runoff Process; Error Back Propagation; Neural Power

\section{Introduction}

Rainfall-runoff is important in activities such as flood control and management, design of hydraulic structures in a watershed, and likewise. Historically, researchers have relied on conventional techniques, either deterministic models, which consider the physics of the underlying process, or systems theoretic/black-box models, which do not. Deterministic models of varying degrees of complexity have been employed in the past for the rainfall runoff process with varying degrees of success. The rainfall runoff is a complex, dynamic, and non-linear process, which is affected by many and often interrelated, physical factors. The influence of these factors and many of their combinations in generating runoff is an extremely complex physical process, and is not clearly understood [1]. Moreover, many of the deterministic rainfall-runoff models need a large amount of data for calibration and validation purposes, and are computationally expensive. As a result, the use of deterministic models of the rainfall-runoff process is viewed rather skeptically by researchers and consequently has not become very popu$\operatorname{lar}[2]$.

Artificial Neural Networks (ANNs) have been proposed as efficient tools for and prediction in hydrology, as black-box models. ANNs are supposed to posses the capability to reproduce the unknown relationship existing between a set of input variables (e.g., rainfall) of the system and one or more output variables (e.g., runoff) [3]. In recent years ANNs have shown exceptional performance as regression tools, especially when used for pattern recognition and function estimation. They are highly nonlinear, and can capture complex interactions among the input variables in a system without any prior knowledge about the nature of these interactions [4]. The main advantage of ANNs is that one does not have to explicitly assume a model form, which is a prerequisite in conventional approaches. Indeed, in ANNs the data points themselves generate a relationship of possibly complicated or orthodox shape. In comparison to the conventional methods, ANNs tolerate imprecise or incomplete data, approximate results, and are less vulnerable to outliers [5]. They are highly parallel, i.e., their numerous independent operations can be executed simultaneously. These characteristics render ANNs to be very suitable tools for handling various hydrological problems. Although application of ANN approach for rainfall-runoff process is recent, it has already produced very encouraging results.

Among various hydrological problems, rainfall-runoff has perhaps received the maximum attention from ANN researchers. In an earlier study, Halff et al. [6] designed a three-layer feedforward ANN using the observed rainfall 
hyetographs as inputs and hydrographs recorded by the US Geological Survey (USGS) at Bellvue, Washington, as outputs. This study opened up several possibilities for rainfall-runoff application using neural networks. Hjelmfelt and Wang [7] developed a neural network based on the unit hydrograph theory for the Goodwater Creek watershed in central Missouri. In an application using two neural networks, Zhu et al. [8] predicted upper and lower bounds on the flood hydrograph in Butter Creek, New York. Smith [9] used a back-propagation ANN model to predict the peak discharge and the time to peak resulting from a single rainfall pattern. Carriere et al. [10] designed and developed a Virtual Runoff Hydrograph System (VROHS) based on ANN to generate runoff hydrograph. Lange [11] introduced a method which generates a special hydrograph (comparable with the unit hydrograph) by using an ANN. Anmala et al. [12] utilized ANNs for runoff predictions in three watersheds in Kansas. The authors found that a direct use of feed forward ANNs without time delayed input does not provide a significant improvement over other regression techniques. Sudheer et al. [13] worked on a data driven algorithm for constructing Artificial Neural Network Rainfall-Runoff Models. Quebec. Chibanga et al. [14] modeled the derived flow series (by simple reservoir routing) and the time series of historic flow measured at the Kafue Hook Bridge (KHB), Kafue River basin in Vietnam, separately using ANNs. Chiang et al. [15] presented a system comparison of two basic types of neural networks, static and dynamic in their study. Jy S. Wu et al. [16] demonstrated the application of ANNs for watershed-runoff and stream-flow forecasts. Sarkar et al. [17] developed back propagation ANN runoff models to simulate and forecast daily runoff for a part of the Satluj river basin of India. Kisi [18] presented a comparison of different artificial neural network algorithms for short term daily streamflow forecasting. Kalteh [19] developed rainfall-runoff model using ANN and described different approaches including Neural Interpretation Diagram, Garson's algorithm, and randomization approach to understand the relationship learned by the ANN model. Modarres [20] carried out a comprehensive multicriteria validation test for rainfall-runoff by artificial neural networks with 17 global statistics and 3 additional non-parametric tests through a case study of the Plasjan Basin in the western region of the Zayandehrud watershed, Iran. Dorum et al. [21] tried to set up rainfall-runoff relationship by using ANN and Adaptive Neuro Fuzzy Interference Systems (ANFIS) models at Flow Observation Stations on seven sites in Susurluk Basin.

A rainfall-runoff model can be one of two types-an event based rainfall-runoff model or a continuous rainfall-runoff model. Application of ANN approach for the continuous rainfall-runoff process is numerous but that of the event based process are limited. The present study focuses on the of an event-based rainfall-runoff process. Such ANN models are very useful in real time flood forecasting.

\section{Methodology}

An ANN is a computing system made up of a highly interconnected set of simple information processing elements, analogous to a neuron, called units. The neuron collects inputs from both a single and multiple sources and produces output in accordance with a predetermined non-linear function. An ANN model is created by interconnection of many of the neurons in a known configuration. The primary elements characterising the neural network are the distributed representation of information, local operations and non-linear processing. The theory of ANN has been described in many books such as Haykin [5] and Yegnanarayana [22].

The main principle of neural computing is the decomposition of the input-output relationship into series of linearly separable steps using hidden layers [5]. Generally there are four distinct steps in developing an ANNbased solution. The first step is the data transformation or scaling. The second step is the network architecture definition, where the number of hidden layers, the number of neurons in each layer, and the connectivity between the neurons are set. In the third step, a learning algorithm is used to train the network to respond correctly to a given set of inputs. Lastly, comes the validation step in which the performance of the trained ANN model is tested through some selected statistical criteria.

Large variation in the input data can slow down or even prevent the training of the network. To overcome this potential problem, the data are usually scaled using linear, logarithmic, or normal transformations. It is also important that the absolute input values are scaled to avoid asymptotic issues [5]. In the present study, the input data for a variable $x$ were standardised through the ANN software, Neural Power [23].

There are three basic layers or levels of data processing units viz., the input layer, the hidden layer and the output layer. Each of these layers consists of processing units called nodes of the neural network. The number of input nodes, output nodes and the nodes in the hidden layer depend upon the problem being studied. If the number of nodes in the hidden layer is small, the network may not have sufficient degrees of freedom to learn the process correctly. If the number is too high, the training will take a long time and the network may sometimes over-fit the data [24].

The process of determining ANN weights is called training, which forms the interconnection between neurons. The ANNs are trained with a training set of input 
and known output data. At the beginning of training, the initial value of weights can be assigned randomly or based on experience. The learning algorithm systematically changes the weights such that for a given input, the difference between the ANN output and the actual output is small. Many learning examples are repeatedly presented to the network, and the process is terminated when this difference is less than a specified value. At this stage, the ANN is considered trained. An ANN is better trained as more input data are used. Several learning algorithms have been reported in the literature. In the present study, the most widely used three layer feed forward error back propagation algorithm [25] has been used for training.

After training is over, the ANN performance is validated. Depending on the outcome, either the ANN has to be re-trained or it can be implemented for its intended use. A large number of statistical criteria are available to compare the goodness of any given model. The performance evaluation statistics used for ANN training in the present work are root mean square error (RMSE), coefficient of correlation (R) and coefficient of determination (DC). These parameters have been determined using the following equations [23].

$$
\begin{aligned}
& \mathrm{RMSE}=\sqrt{\frac{\sum_{i=1}^{n}\left(Q_{i}-q_{i}\right)^{2}}{n}} \\
& \mathrm{R}=\frac{\sum_{i=1}^{n}\left(Q_{i}-\bar{Q}\right)\left(q_{i}-\bar{q}\right)}{\sqrt{\sum_{i=1}^{n}\left(Q_{i}-\bar{Q}\right)^{2}\left(q_{i}-\bar{q}\right)^{2}}}
\end{aligned}
$$

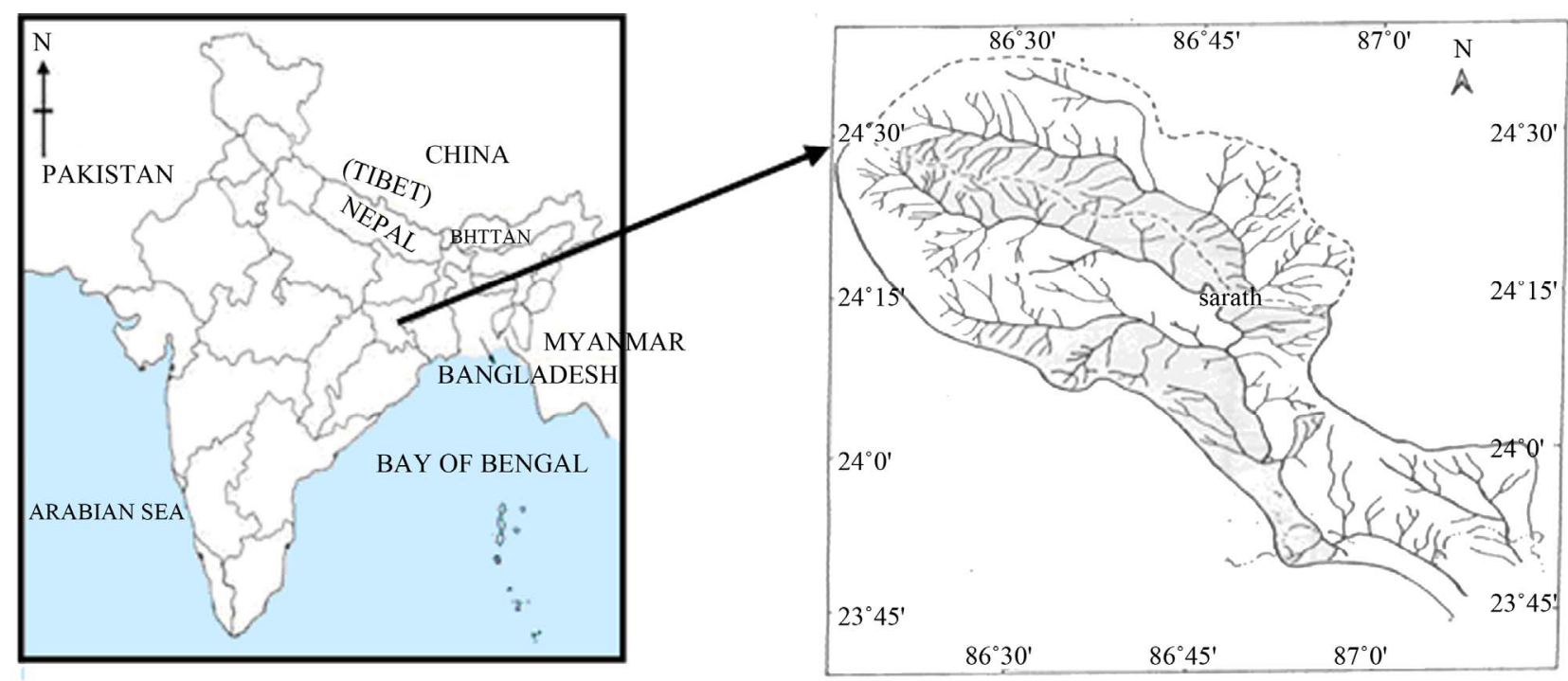

Figure 1. Index map of part of Ajay River Basin in Jharkhand (India) with catchment defined by Sarath Gauging Site.

$$
\mathrm{DC}=\frac{\sum_{i=1}^{n}\left(Q_{i}-\bar{Q}\right)^{2}-\sum_{i=1}^{n}\left(Q_{i}-\bar{q}\right)^{2}}{\sqrt{\sum_{i=1}^{n}\left(Q_{i}-\bar{Q}\right)^{2}}}
$$

where $\bar{Q}=\frac{1}{n} \sum_{i=1}^{n} Q_{i}, \quad \bar{q}=\frac{1}{n} \sum_{i=1}^{n} q_{i}$,

$Q=$ observed discharge (cumec), $q=$ calculated discharge (cumec).

\section{Study Area and Data Used}

For the present study, Ajay river basin up to Sarath gauging site forms the study area. The catchment of the Ajay river spreads between Latitude $23^{\circ} 25^{\prime} \mathrm{N}$ to $24^{\circ} 35^{\prime} \mathrm{N}$ and Longitude $86^{\circ} 15^{\prime} \mathrm{E}$ to $88^{\circ} 15^{\prime} \mathrm{E}$. The Ajay river system originates in the low hills near Deoghar in the Santhal Pargana district of Jharkhand state and flows in a SouthEasterly direction passing through Monghyr district of Jharkhand state and Birbhum and Burdwan district of West Bengal. Ajay River ultimately falls into the river Bhagirathi at Katwa about $216 \mathrm{~km}$ upstream of Calcutta. The Sarath gauging site, established near village Sarath and about $160 \mathrm{~m}$ upstream of Sarath-Madhupur Road Bridge, is maintained by Water Resources Department, Govt of Jharkhand. The geographical location of the site is $24^{\circ} 13^{\prime} 45^{\prime \prime} \mathrm{N}$ latitude and $86^{\circ} 50^{\prime} 43^{\prime \prime} \mathrm{E}$ longitude. The catchment area up to the site is $1191.40 \mathrm{sq} \cdot \mathrm{km}$. The length of Ajay River up to Sarath gauging site is 82.18 $\mathrm{sq} \cdot \mathrm{km}$. Figure 1 shows the index map of the part of Ajay river basin lying in Jharkhand state along with the catchment defined by Sarath gauging site which forms the study area. Table 1 gives the details of periods of various storms whose rainfall-runoff data have been used in the study. 
Table 1. Periods of various rainfall-runoff events.

\begin{tabular}{cc}
\hline S. No. & Period of the Events \\
\hline 1 & 13.08 .1977 at 09 hrs. to 13.08 .1977 at $20 \mathrm{hrs}$. \\
2 & 05.08 .1978 at 21 hrs. to 06.08 .1978 at 02 hrs. \\
3 & 16.08 .1979 at 05 hrs. to 16.08 .1979 at 16 hrs. \\
4 & 26.08 .1980 at 15 hrs. to 27.08 .1980 at 07 hrs. \\
5 & 22.08 .1982 at 24 hrs. to 23.08 .1982 at 06 hrs. \\
6 & 12.09 .1987 at 13 hrs. to 12.09 .1987 at 24 hrs. \\
\hline
\end{tabular}

\section{Case Study}

\subsection{Input Variables}

The first step in developing an ANN model is to identify the input and output variables. The output from the model is the runoff at time step $t, \mathrm{R}_{\mathrm{t}}$. The input variables have been selected based on the concepts of time of concentration and recession of a storm hydrograph. The time of concentration of the Ajay river basin was observed to lie between 21 to 22 hours. With a time of concentration of 22 hours and a time interval of 1 hour, the number of time steps for the past for which rainfall must be considered as input in the ANN models should be $22(=22 / 1)$. Further it was found that the runoff in the immediate past was a more significant variable compared to the runoff in the distant past, and hence it has been applied in all the ANN models. Therefore, there were 26 input variables $\left(\mathrm{P}_{\mathrm{t}}, \mathrm{P}_{\mathrm{t}-1,}, \mathrm{P}_{\mathrm{t}-2}, \cdots \cdots \mathrm{P}_{\mathrm{t}-22}, \mathrm{R}_{\mathrm{t}-1}, \mathrm{R}_{\mathrm{t}-2}\right)$ and one output variable $\left(\mathrm{R}_{\mathrm{t}}\right)$.

\subsection{ANN Model Development}

In estimation of parameters of a hydrologic model, the available data are divided in two parts. The first part is used to calibrate the model and the second, to validate it. This practice is known as "split-sample" test. The length of calibration data depends upon the number of parameters to be estimated. The general practice is to use half to two-third of the data for calibration and the remaining for validation.

Six isolated storm events were chosen for the study. The 1-hourly rainfall runoff data were available for flood seasons. ANN models have been developed considering hourly data for four flood events for training and two flood events for testing. On a rotation basis, data from four storms have been used for training, while data from two storms have been used for testing network performance. Various combinations of the flood events considered for training and testing are given in Table 2.

A back-propagation ANN with the generalized delta rule as the training algorithm has been employed in this study. The ANN package Neural Power downloaded from the internet has been used for the ANN model development. The structure for all simulation models are three layer BPANN which utilizes a non-linear sigmoid activation function uniformly between the layers. Nodes
Table 2. Description of various ANN models for training and testing.

\begin{tabular}{ccc}
\hline ANN Model & $\begin{array}{c}\text { Events used in Training } \\
\text { (Calibration) }\end{array}$ & $\begin{array}{c}\text { Events used in Testing } \\
\text { (Validation) }\end{array}$ \\
\hline ANN-1 & Events 1, 2, 3, 4 & Events 5, 6 \\
ANN-2 & Events 2, 3, 4, 5, & Events 6, 1 \\
ANN-3 & Events 3, 4, 5, 6 & Events 1, 2 \\
ANN-4 & Events 4, 5, 6, 1 & Events 2, 3 \\
ANN-5 & Events 5, 6, 1, 2 & Events 3, 4 \\
ANN-6 & Events 6, 1, 2, 3 & Events 4, 5 \\
\hline
\end{tabular}

in the input layer are equal to number of input variables, nodes in hidden layer are varied from 18 (default value by the NP package for 26 input nodes) to approximately double of input nodes [8] and the nodes in the output layer is one as the models provide single output. It was found that 18 hidden nodes give the best results. So for all the ANN models, 18 nodes in the hidden layer have been considered.

Number of input nodes in input layer $=26$

Number of hidden layers $=1$

Number of hidden nodes $=18$

Number of nodes in output layer $=1$

According to Hsu et al. [26], three-layer feed forward ANNs can be used to model real-world functional relationships that may be of unknown or poorly defined form and complexity. Therefore, only three-layer networks were tried in this study.

The modeling of ANN initiated with the normalization (re-scaling) of all inputs and output with the maximum value of respective variable reducing the data in the range 0 to 1 to avoid any saturation effect that may be caused by the use of sigmoid function (accomplished through the Neural Power package). All interconnecting links between nodes of successive layers were assigned random values called weights. A constant value of 0.15 and 0.8 respectively has been considered for learning rate $\alpha$ and momentum term $\beta$ selected after hit and trials. The quick propagation (QP) learning algorithm has been adopted for the training of all the ANN models. QP is a heuristic modification of the standard back propagation and is very fast. The network weights were updated after presenting each pattern from the learning data set, rather than once per iteration. The criteria selected to avoid over training was through generalization of ANN for which the developed model was simultaneously checked for its improvement on verification data on each iteration. The training was continued until there was an improvement in the performance of the model in both calibration and verification periods. The performance of the model was tested through the criterion discussed earlier.

\section{Results and Discussion}

The values of the performance criteria from various models for both training (calibration) and testing (valida- 
tion) data sets are presented in Table 3. It can be seen from Table 3 that, in general, RMSE is found to be smaller (lowest for ANN-4) and the ANN estimates are closer to the observed values. Coefficient of correlation (R) is another indicator of goodness of fit and it is seen from Table 3 that, $\mathrm{R}$ is also quite high in all the cases of training and tested data sets (highest for ANN-2). The determination coefficient (DC) is also closer to unity, for all the cases of training test data (highest for ANN-2). Thus, the estimations by ANN are found to yield all the three indices with acceptable accuracy.

From Table 3, it is clear that the ANN-2 model outperforms all the other models. This model consists of four flood events namely, events 2, 3, 4, and 5 for training and events 6 and 1 for testing. It is to be noted that the flood event 2 consists of the lowest as well as the highest numerical values of runoff. Moreover, the patterns covered by the four flood events of ANN-2 for training are also highest (270) compared to all the other models. So the performance of ANN-2 model is the best. This conforms to the general fact that an ANN is better trained as more input data are used.

Figure 2 presents a plot between observed and simulated runoff for ANN-2 model during testing and shows a

Table 3. Comparative performance of various ANN models.

\begin{tabular}{cccccc}
\hline \multirow{2}{*}{ ANN Model } & \multicolumn{2}{c}{ Calibration (Training) } & \multicolumn{3}{c}{ Verification (Testing) } \\
\cline { 2 - 6 } & RMSE (cumec) & R & DC & R & DC \\
\hline ANN-1 & 16.382 & 0.998 & 0.996 & 0.832 & 0.61 \\
ANN-2 & 8.375 & 0.999 & 0.999 & 0.989 & 0.977 \\
ANN-3 & 11.685 & 0.999 & 0.997 & 0.941 & 0.675 \\
ANN-4 & 7.775 & 0.999 & 0.998 & 0.975 & 0.933 \\
ANN-5 & 12.78 & 0.998 & 0.997 & 0.968 & 0.934 \\
ANN-6 & 11.913 & 0.999 & 0.998 & 0.952 & 0.766 \\
\hline
\end{tabular}

high correlation between the two. The errors are more for the lower discharge values and there are no errors in the peak values.

The observed and simulated flood hydrographs for the events 1 to 6 are shown in Figure 3. These simulated flood hydrographs are based on the best performing ANN model, i.e., ANN-2 model. It can be seen that there is a perfect match between the observed and simulated flood hydrographs for the flood events 2, 3, 4 and 5. This is because these four events together have been used for training the ANN-2 model. However, very good match between the observed and simulated flood hydrographs is also there for the events 1 and 6 which were not used for the training. The coefficient of correlation is as high as 0.925 and 0.927 for flood events 1 and 6 respectively. The results demonstrate the capability of ANN technique in simulating the event-based rainfall-runoff process of the Ajay river basin accurately. The results of the present study comply with the demonstrated capability of ANN technique as presented by various investigators.

\section{Conclusion}

The application of artificial neural network (ANN) methodology for modeling events of rainfall-runoff in a medium size catchment of the Ajay River in Jharkhand (India) is presented. Back propagation models have been designed and developed for the hourly runoff simulation of Ajay river basin at Sarath gauging site. Various combinations of the flood events have been considered during training. The performance of each model structure has been evaluated using common performance criteria, namely, root mean square error (RMSE), coefficient of

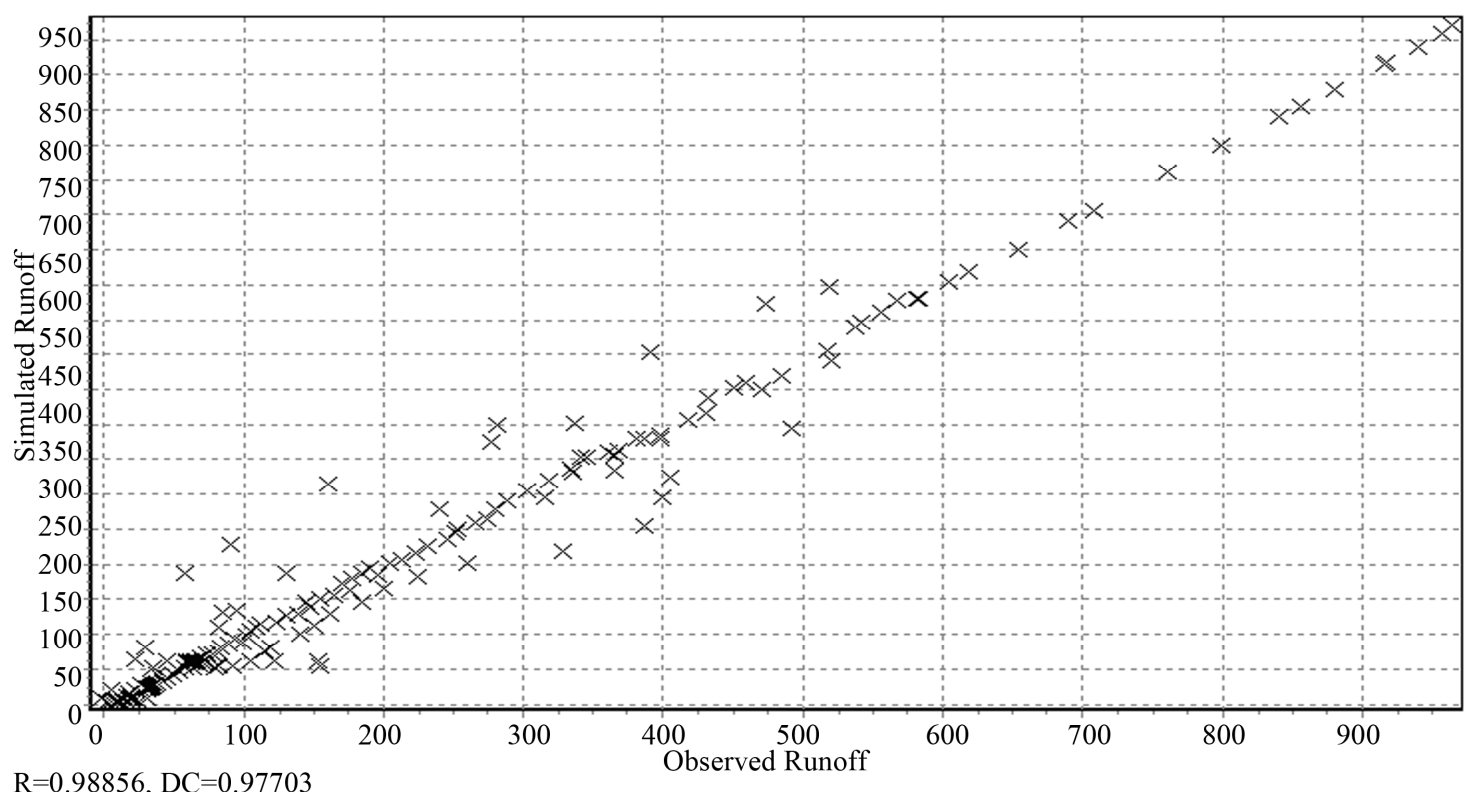

Figure 2. Observed v/s simulated runoff at Sarath from ANN-2 during testing. 

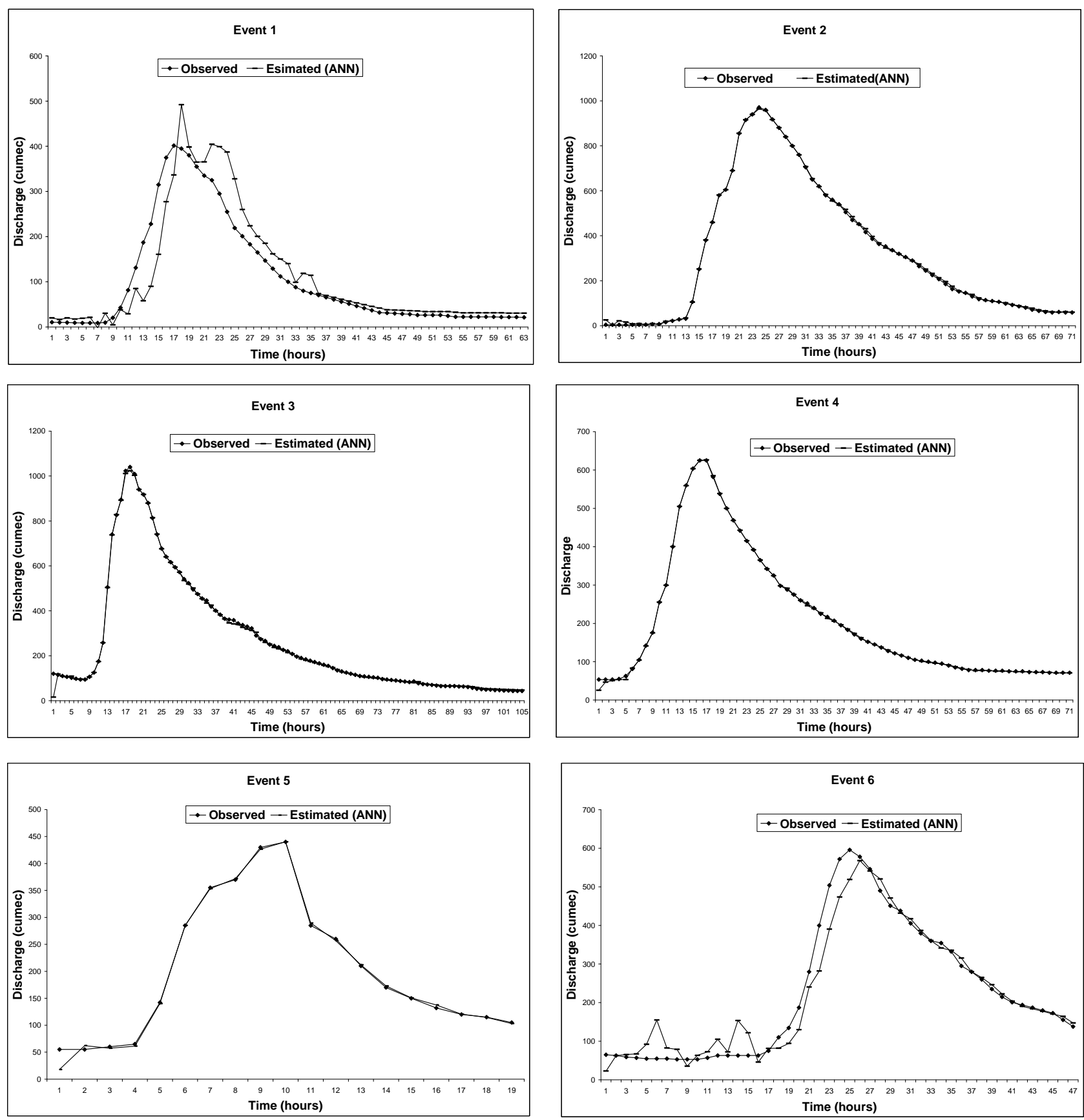

Figure 3. Runoff hydrographs various flood events from ANN-2 during testing.

correlation (R), and coefficient of determination (DC). The results obtained in the present study have been able to demonstrate that the ANN models are able to provide a good representation of an event-based rainfall-runoff process.

\section{Acknowledgements}

We thank the Maroochy Shire project working group, led by Damian McGarry, who provided the wide range of data and analysis for the analysis. We also thank Dr.
Heinz Schandl of CSIRO for suggestions to improve the paper.

\section{REFERENCES}

[1] B. Zhang and S. Govindaraju, "Prediction of Watershed Runoff Using Bayesian Concepts and Modular Neural Networks," Water Resources Research, Vol. 36, No. 3, 2000, pp. 753-762. doi:10.1029/1999WR900264

[2] R. B. Grayson, I. D. Moore and T. A. McMahon, "Physically Based Hydrologic-2. Is the Concept Realistic?” 
Water Resources Research, Vol. 28, No. 10, 1992, pp. 2659-2666. doi:10.1029/92WR01259

[3] K. Chakraborty, K. Mehrotra, C. K. Mohan and S. Ranka, "Neural Networks and Their Applications," Review of Scientific Instruments, Vol. 65, 1992, pp. 1803-1832.

[4] D. Hammerstrom, "Neural Networks at Work," IEEE Spectrum, Vol. 30, No. 7, 1993, pp. 46-53. doi:10.1109/6.222230

[5] S. Haykin, "Neural Networks-A Comprehensive Foundation,” Macmillan, New York, 1994.

[6] A. H. Halff, H. M. Halff and M. Azmoodeh, "Predicting Runoff from Rainfall Using Neural Network,” Proceedings Engineering Hydrolgy, American Society of Civil Engineers, New York, 1993, pp. 760-765.

[7] A. T. Hjelmfelt and M. Wang, "Artificial Neural Networks as Unit Hydrograph applications," Proceedings Engineering Hydrolgy, American Society of Civil Engineers, New York, 1998, pp. 760-765.

[8] M. Zhu, M. Fujita and N. Hashimoto, "Application of Neural Networks to Runoff Prediction,” In: K. W. Hipel, et al., Eds., Stochastic and Statistical Method in Hydrology and Environmental Engineering, Vol. 3, Kluwer, Dordrecht, 1994, pp. 205-216.

[9] J. Smith and R. N. Eli, "Neural Network Models of Rainfall-Runoff Processes," Journal of Water Resources Planning \& Management, American Society of Civil Engineers, Vol. 121, No. 6, 1995, pp. 499-508. doi:10.1061/(ASCE)0733-9496(1995)121:6(499)

[10] P. Carriere, S. Mohaghegh and R. Gaskari, "Performance of a Virtual Runoff Hydrograph System,” Journal of Computing in Civil Engineering, American Society of Civil Engineers, Vol. 122, No. 6, 1996, pp. 421-427.

[11] N. T. G. Lange, “Advantages of Unit Hydrograph Derivation by Neural Networks,” In: V. Babovic and C. L. Larsen, Eds., Hydroinformatics, Vol. 2, Balkema, Rotterdam, 1998.

[12] J. Anmala, B. Zhang and R. S. Govindraju, "Comparison of ANNs and Empirical Approaches for Predicting Watershed Runoff," Journal of Water Resources Planning \& Management, American Society of Civil Engineers, Vol. 126, No. 3, 2000, pp. 156-166. doi:10.1061/(ASCE)0733-9496(2000)126:3(156)

[13] K. P. Sudheer, A. K. Gosain and K. S. Ramasastri, “A Data Driven Algorithm for Constructing Artificial Neural Network Rainfall-Runoff Models," Hydrological Processes, Vol. 16, No. 6, 2002, pp. 1325-1330. doi:10.1002/hyp.554

[14] R. Chibanga, J. Berlamont and J. Vandewalle, "Modelling and Forecasting of Hydrological Variables Using Artificial Neural Networks: The Kafue River Sub-Basin,”
Hydrological Sciences Journal, Vol. 48, No. 3, 2003, pp. 363-379. doi:10.1623/hysj.48.3.363.45282

[15] Y. Chiang, L. Chang and F. Chang, "Comparison of Static Feed Forward and Dynamic-Feedback Neural Networks for Rainfall-Runoff,” Journal of Hydrology, Vol. 290, 2004, pp. 297-211 doi:10.1016/j.jhydrol.2003.12.033

[16] J. S. Wu, P. E. Han, J. Annambhotla and S. Bryant, “Artificial Neural Networks for Forecasting Watershed Runoff and Stream Flows,” Journal of Hydrologic Engineering, ASCE, Vol. 10, No. 3, 2005, pp. 216-222. doi:10.1061/(ASCE)1084-0699(2005)10:3(216)

[17] A. Sarkar, A. Agarwal and R. D. Singh, “Artificial Neural Network Models for Rainfall-Runoff Forecasting in a Hilly Catchment," Journal of Indian Water Resources Society, Vol. 26, No. 3-4, 2006, pp. 1-4.

[18] O. Kisi, "Streamflow Forecasting Using Different Artificial Neural Network Algorithms," Journal of Hydrologic Engineering, American Society of Civil Engineers, Vol. 12, No. 5, pp. 532-539. doi:10.1061/(ASCE)1084-0699(2007)12:5(532)

[19] A. M. Kalteh, "Rainfall-Runoff Using Artificial Neural Networks (ANNs) and Understanding,” Caspian Journal of Environmental Science, Vol. 6, No. 1, 2008. pp. 53-58.

[20] R. Modarres, "Multi-Criteria Validation of Artificial Neural Network Rainfall-Runoff,” Hydrology and Earth System Sciences, Vol. 13, 2009, pp. 411-421. doi:10.5194/hess-13-411-2009

[21] A. Dorum, A. Yarar, M. F. Sevimli and M. Onucyildiz, "The Rainfall-Runoff Data of Susurluk Basin," Expert Systems with Applications: An International Journal, Vol. 37, No. 9, 2010, pp. 6587-6593.

[22] B. Yegnanarayana, “Artificial Neural Networks,” Prentice-Hall of India Pvt. Ltd., New Delhi, 1999.

[23] Neural Power, "Neural Networks Professional Version 2.0,” CPC-X Software, 2003.

[24] N. Karunanithi, W. J. Grenney, D. Whitley and K. Bovee, "Neural Networks for River Flow Prediction," Journal of Computing in Civil Engineering, ASCE, Vol. 8, No. 2, 1994, pp. 201-220. doi:10.1061/(ASCE)0887-3801(1994)8:2(201)

[25] D. E. Rumelhart, G. E. Hinton and R. J. Williams, "Learning Internal Representations by Error Propagation: Parallel Distributed Processing, Vol. I,” MIT Press, Cambridge, 1986, pp. 318-362.

[26] K. Hsu, H. V. Gupta and S. Sorooshian, "Artificial Neural Network of the Rainfall-Runoff Process," Water Resources Research, Vol. 31, No. 10, 1995, pp. 2517-2530. doi:10.1029/95WR01955 